\title{
Assessing the Added Value of Dynamical Downscaling Using the Standardized Precipitation Index
}

\author{
Jared H. Bowden, ${ }^{1}$ Kevin D. Talgo, ${ }^{1}$ Tanya L. Spero, ${ }^{2}$ and Christopher G. Nolte ${ }^{2}$ \\ ${ }^{1}$ Institute for the Environment, University of North Carolina at Chapel Hill, 100 Europa Drive, Campus Box 1105 (27599-1105), \\ Chapel Hill, NC 27517, USA \\ ${ }^{2}$ Atmospheric Modeling and Analysis Division, National Exposure Research Laboratory, \\ United States Environmental Protection Agency, 109 TW Alexander Drive, Research Triangle Park, NC 27711, USA
}

Correspondence should be addressed to Jared H. Bowden; jhbowden@unc.edu

Received 6 April 2015; Accepted 11 August 2015

Academic Editor: Eduardo García-Ortega

Copyright (c) 2016 Jared H. Bowden et al. This is an open access article distributed under the Creative Commons Attribution License, which permits unrestricted use, distribution, and reproduction in any medium, provided the original work is properly cited.

\begin{abstract}
In this study, the Standardized Precipitation Index (SPI) is used to ascertain the added value of dynamical downscaling over the contiguous United States. WRF is used as a regional climate model (RCM) to dynamically downscale reanalysis fields to compare values of SPI over drought timescales that have implications for agriculture and water resources planning. The regional climate generated by WRF has the largest improvement over reanalysis for SPI correlation with observations as the drought timescale increases. This suggests that dynamically downscaled fields may be more reliable than larger-scale fields for water resource applications (e.g., water storage within reservoirs). WRF improves the timing and intensity of moderate to extreme wet and dry periods, even in regions with homogenous terrain. This study also examines changes in SPI from the extreme drought of 1988 and three "drought busting" tropical storms. Each of those events illustrates the importance of using downscaling to resolve the spatial extent of droughts. The analysis of the "drought busting" tropical storms demonstrates that while the impact of these storms on ending prolonged droughts is improved by the RCM relative to the reanalysis, it remains underestimated. These results illustrate the importance and some limitations of using RCMs to project drought.
\end{abstract}

\section{Introduction}

Drought impacts more people than any other natural disaster and is the most costly of all natural disasters with an estimated $\$ 6-\$ 8$ billion in global damage annually $[1,2]$. Historical records suggest increasingly severe and widespread droughts have occurred over recent decades, a trend that is projected to persist through the 21st century [3]. Global climate models (GCMs) are critical tools for drought projection because they can simulate the large-scale atmospheric circulation response to changes in radiative forcing. However, the coarse resolution of most GCMs may limit the ability to project regional droughts. Regional climate models (RCMs) are typically used to downscale GCM fields and this dynamically downscaled output may be an important resource for projecting changes in regional droughts. Many coordinated international efforts with RCMs are underway (e.g., CORDEX [4]) or completed (e.g., NARCCAP [5], PRUDENCE [6], and ENSEMBLES [7]) to represent the regional climatology at higher resolution. For instance, using a RCM can improve the representation of land use and land cover [8] and resolve mesoscale circulations and feedbacks [9-11].

Droughts are commonly associated with large-scale shifts in the atmospheric circulation and/or sea surface temperature anomalies [12-14]. These large-scale features are resolved by GCMs, which have projected changes such as the poleward shift in the Hadley cell [15] or the westward migration of the Bermuda High [16]. Therefore, RCMs, which are forced by GCM fields, may be limited in their ability to improve the characterization of widespread droughts because such droughts are driven by the large-scale atmospheric circulation resolved by GCMs. In addition, RCMs typically use climatological albedo values that can limit the land-surfaceatmosphere feedbacks that affect drought [17]. However, 
RCMs may add value beyond the driving GCM at regional to local scales by improving the precipitation variability (i.e., extremes) that is important for describing the regional climate or ending long-term droughts. Maule et al. [18] evaluated RCMs within the ENSEMBLES project over Europe using the Standardized Precipitation Index (SPI) and Palmer Drought Severity Index for hindcast simulations. They found that RCMs in ENSEMBLES could capture observed drought features, but those RCMs performed poorly in complex terrain regions and often did not correctly simulate the magnitude of droughts. Russo et al. [19] also evaluated RCMs within the ENSEMBLES project and found that a nonstationary form of the SPI reveals robust changes in extreme dry and wet years/seasons in a future climate over Europe. Overall, because droughts are commonly associated with shifts in the large-scale atmospheric circulation and there are limitations with many RCMs using climatological albedo values, it is important to demonstrate the added value of a RCM for a drought metric such as the SPI. To our knowledge, this type of comparison has not been performed previously and complements prior studies such as Maule et al. [18] and Russo et al. [19].

The objective of this paper is to evaluate hindcast simulations of SPI using the Weather Research and Forecasting (WRF) model [20] for dynamical downscaling over the contiguous United States (CONUS) to quantify the value added by downscaling. In particular, this study identifies the added value of using dynamically downscaled fields to compute SPI for different accumulation periods and different extreme events, including a major drought and "drought busting" tropical storms. Section 2 describes the WRF model setup, and Section 3 describes the SPI. Section 4 contains statistical analyses of SPI over the 18 -year simulation. Section 5 explores changes in SPI during the 1988 North American drought and after the passages of tropical cyclones during the 1990 and 1999 Atlantic hurricane seasons that helped to alleviate drought conditions within the eastern U.S. Discussion and conclusions are provided in Section 6.

\section{WRF Model Setup}

The WRF model version 3.4.1 was run continuously from 1988 to 2005 after a one-month spin-up using a $108-36-\mathrm{km}$, twoway nested domain covering North America (Figure 1). The input data are $2.5^{\circ} \times 2.5^{\circ}$ fields from the National Centers for Environmental Prediction-Department of Energy Atmospheric Model Intercomparison Project (AMIP-II) Reanalysis data [21], hereinafter, R2. R2 data can be considered as perfect lateral boundary conditions, permitting direct comparison with observations, and they have a horizontal resolution that is comparable to many GCMs. WRF was run with a 34-layer configuration with a model top at $50 \mathrm{hPa}$. The physics options follow those used in Otte et al. [22], except that the simulation here used the Kain-Fritsch convective parameterization [23]. The simulation employs analysis nudging on both domains with nudging coefficients following Otte et al. [22]. Analysis nudging has been shown to improve the large-scale atmospheric circulation within WRF [24] as well as the mean and extreme 2-m temperature and

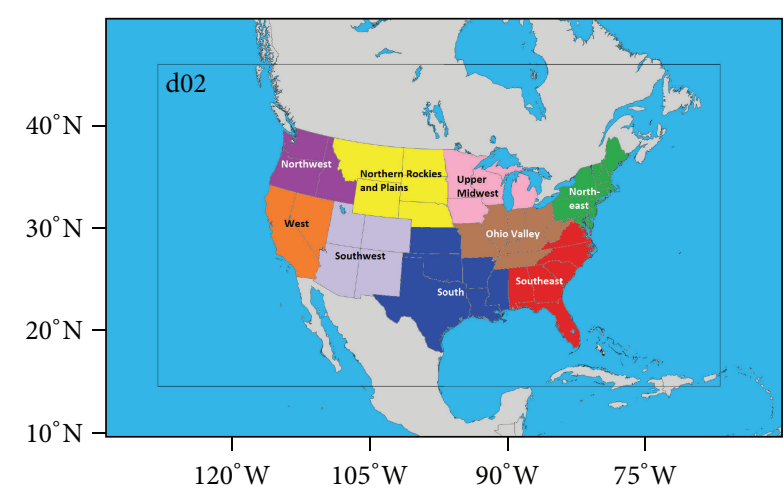

FIGURE 1: WRF 108-km and 36-km (“d02") domains. Shaded regions are the NCDC climate regions.

precipitation $[22,24,25]$ in regional climate modeling forced by historical data.

\section{Standardized Precipitation Index}

This study uses the SPI $[26,27]$ to identify wet and dry periods and classify their severity within the 18 -year simulation period. The SPI is appealing since it is based solely on precipitation, which is readily available from RCMs; other drought indices rely on fields that often need to be derived or inferred from RCM output. The SPI can be applied across many short-term climatic timescales and is equally effective in categorizing wet and dry periods.

To calculate SPI, the long-term monthly precipitation record is fitted to a gamma distribution which is then transformed into a normal distribution so that the mean SPI at each location and over the desired period is zero [28]. The SPI value for the total precipitation over some period (of specific months and of a certain duration) is the number of standard deviations from the climatological mean for the same relative period and timescale. For example, a 3-month SPI at the end of August compares the JuneAugust precipitation total in that particular year with the June-August precipitation totals of all the years on record for that location. Positive SPI values indicate higher than mean precipitation, and negative values indicate lower than mean precipitation. Absolute values of SPI ranging from 1.00 to 1.49 are considered to be moderate events. Absolute values of SPI between 1.50 and 1.99 are classified as severe events. Extreme events, defined as having an absolute value of SPI greater than 2 , occur only $2.3 \%$ of the time [18].

The SPI can be calculated over different accumulation periods (i.e., timescales) ranging from one month up to 72 months. Changing the accumulation period in the SPI can be used to differentiate between various types of drought conditions. SPI timescales in the 1- to 3-month range can be used for applications that respond to short-term precipitation anomalies, such as meteorological drought, soil moisture retention, and agriculture. SPI timescales in the 6- to 12month range can be used to assess impacts to groundwater, streamflow, and reservoir levels. 

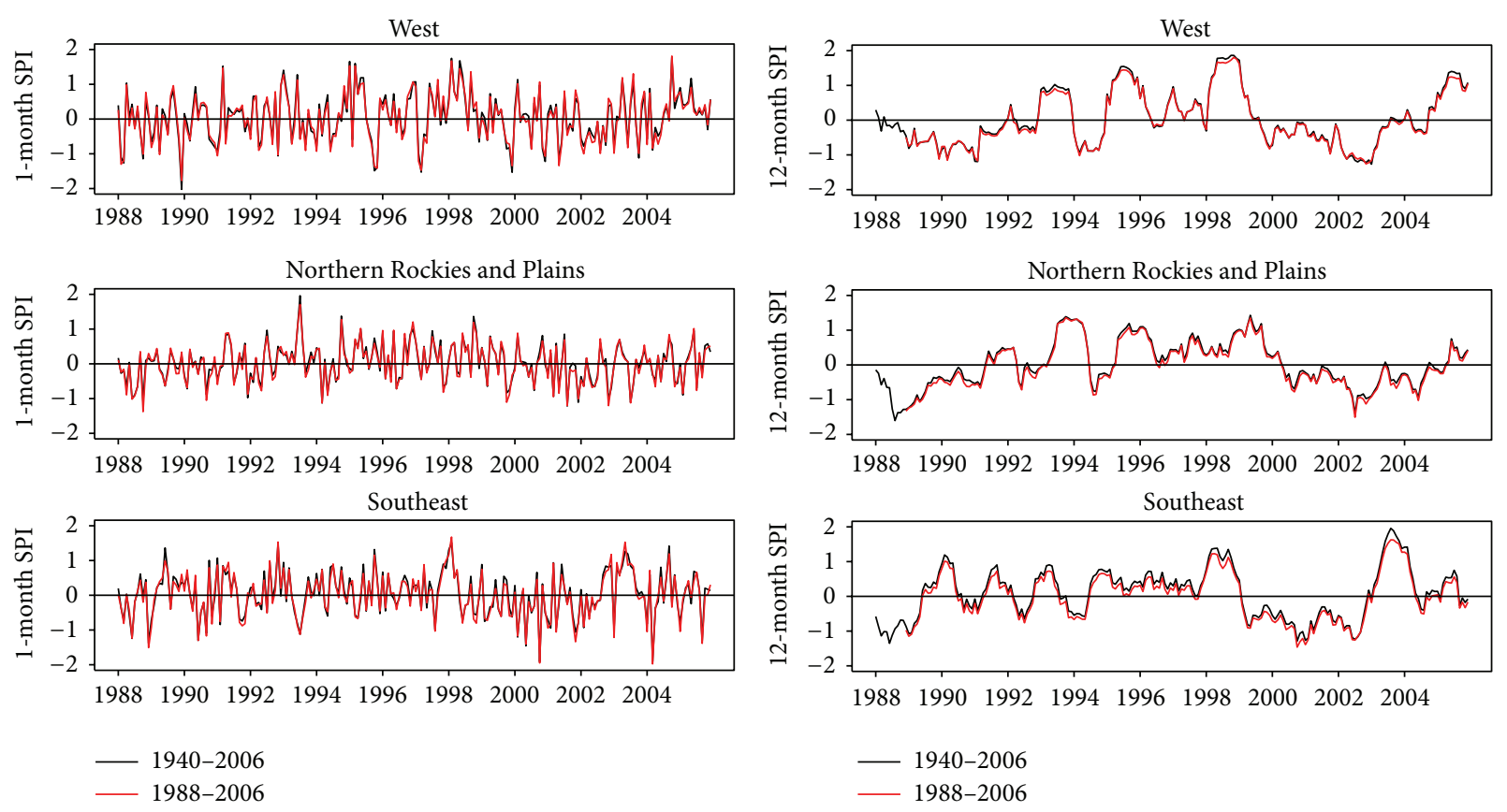

(a)

(b)

FIGURE 2: One-month (a) and 12-month (b) accumulated SPI values computed using PRISM climatological records of 1940-2006 ("long record," black) and 1988-2006 ("short record," red).

\section{SPI Statistical Evaluation}

In this study, we use precipitation data from the ParameterElevation Regressions on Independent Slopes Model (PRISM) [29] as the observational basis to assess the presence and severity of flooding or drought. PRISM is based on precipitation station data and a climate-elevation regression that assigns weights to stations based primarily on the physiographic similarity of the station to the grid cell [29]. The SPI is calculated independently for monthly precipitation fields from WRF, R2, and PRISM over accumulation periods of $1,3,6$, and 12 months. The PRISM products are available monthly at a $4-\mathrm{km}$ resolution, and we upscaled the precipitation data to the $36-\mathrm{km}$ WRF grid using a weighted area average. Data from PRISM are only available over the CONUS, so the analysis is restricted to the CONUS. The statistical evaluations in this paper are based on area averages for the National Climatic Data Center U.S. climate regions (see Figure 1).

4.1. Examining Historical Record Length as a Basis for Computing SPI. This study examines SPI using 18 years of WRF model output rather than 20-30 years of climatological baseline [30]. Wu et al. [31] advise users to be aware of the numerical differences of SPI values when considering the length of record. They demonstrate that SPI values computed from different record lengths are highly correlated and consistent when the gamma distributions of precipitation over the time periods are similar. In light of this, we compare the PRISM SPI values both temporally and spatially for a "short" record (1988-2006) that aligns closely with the WRF simulation period and a "long" record (1940-2006) for different accumulation periods and for the regions shown in Figure 1. Figure 2 compares the SPI values calculated for the 1and 12-month accumulation periods (the shortest and longest examined here) for the West, Northern Rockies and Plains, and Southeast regions. The largest difference between the SPIs for the short and long periods in Figure 2, considering dry conditions (SPI $<-1$ ), is the SPI for the 12-month period ending in November 2000 for the Southeast region, which shows a difference (long record minus short) of 0.24 . Overall, the SPI values are comparable between the short and long climatological records, which gives us confidence that the 18year historical record is sufficient for evaluating SPI over 1-12 months of accumulation periods.

Figure 3 compares the spatial fields of the SPI for the 12month period ending in November 2000 using the short and long climatological records. Figure 3 shows that the intensity and spatial extent of the Southeast drought are larger using the shorter record, as extreme drought conditions (SPI < -2) are characterized to extend through most of Mississippi and Alabama and parts of Georgia, Florida, Arkansas, Texas, and Louisiana. The transitions from dry to wet regions are generally consistent between the two records. Overall, comparisons of SPI computed from both record lengths demonstrate that using the shorter record is sufficient to perform the statistical analysis within the NCDC regions.

4.2. Demonstrating Added Value of Computing SPI from Downscaled Fields. Comparing the SPI time series from 


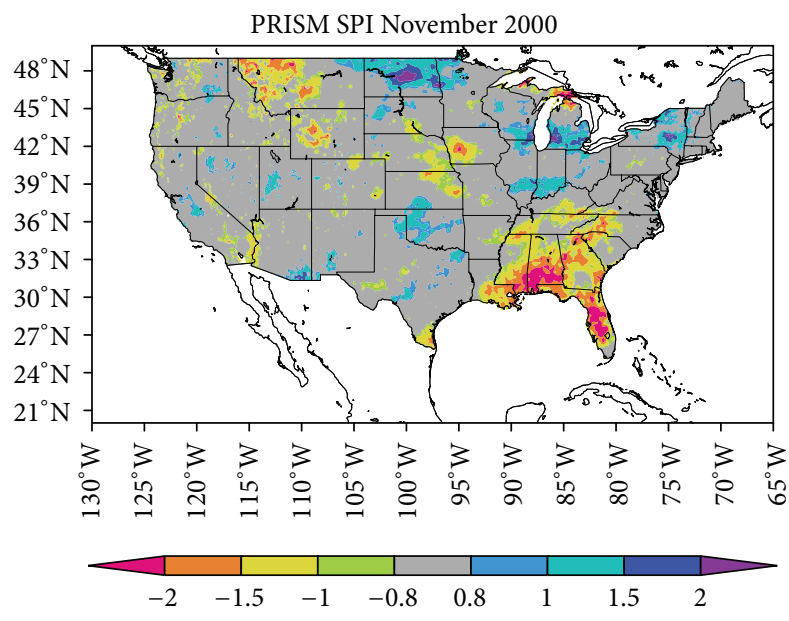

(a)

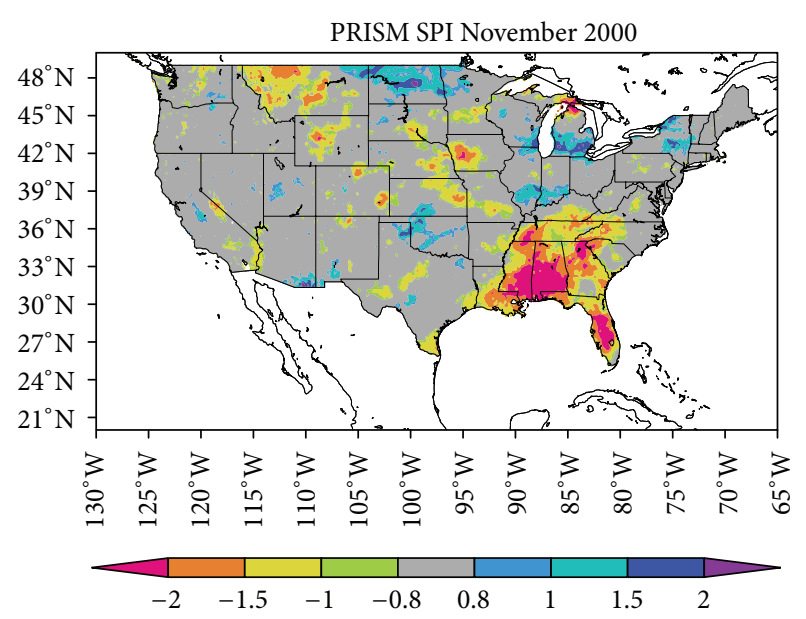

(b)

FIGURE 3: 12-month SPI ending in November 2000 computed using PRISM for (a) 1940-2006 (long record) and (b) 1988-2006 (short record).

WRF and R2 with PRISM can quantify the added value of using downscaled fields. Figure 4(a) shows the correlation coefficient between regionally averaged PRISM and WRF SPI values for different accumulation periods within each climate region. The correlation is higher than 0.8 in each climate region for most timescales. The Northwest, West, and Northeast regions have the highest correlations $(>0.9$ at all timescales) while the Northern Rockies and Plains and the Upper Midwest have the lowest correlations. As with WRF, R2 also has higher and lower regional correlations in these regions (Figure 4(b)). Additionally, both WRF and R2 have a higher correlation for the shorter accumulation periods of 1-3 months versus the longer accumulation periods of 6-12 months. These interregional similarities in correlation with PRISM SPI suggest the atmospheric forcing resolved by the large-scale model strongly influences the RCM simulation when calculating SPI.

Regions with the highest correlation of SPI between PRISM and either R2 or WRF do not necessarily indicate added value. The difference in the correlation coefficients between WRF and R2 is used to illustrate value added by downscaling. Figure 4(c) shows the difference in the correlation coefficient (WRF minus R2) at different SPI timescales for each climate region. The largest improvements in correlation of SPI by downscaling occur east of the Rockies, particularly in the Ohio Valley region which generally had the lowest correlation of any region between PRISM and R2. These improvements demonstrate that SPI can be improved by downscaling in areas without complex terrain. The added value by downscaling may be a result of improvements in simulating the weather patterns in the lee of the Rocky Mountains because the terrain is better resolved in WRF relative to R2 and/or improvements in representing the local atmospheric stability in WRF. Downscaling R2 with WRF generally provides greater improvement in the correlation with PRISM as SPI accumulation period length increases (Figure 4(c)) despite WRF's correlation being the highest for shorter accumulation periods (Figure 4(a)). The increase in correlation suggests that added value for SPI depends on the accumulation period and that RCMs may provide relatively more value for long-term dry or wet periods that are important for water resource management.

To explore the added value further, the critical success index (CSI) [32] is used to evaluate how well R2 and WRF characterize moderate to extreme wet and dry periods. The CSI is a measure of the skill of SPI exceedances considering hits (events when the SPI modeled by WRF or R2 exceeds \pm 1 and is corroborated by the PRISM data), false alarms (events when the SPI modeled by WRF or R2 exceeds \pm 1 but is not corroborated by the PRISM data), and missed exceedances (events when the SPI by PRISM exceeds \pm 1 but is not corroborated by the WRF nor R2 data). We calculate the CSI as follows:

$$
\begin{aligned}
\operatorname{CSI}(\%)= & \frac{\text { HITS }}{\text { HITS + MISSES + FALSE ALARMS }} \\
& \times 100,
\end{aligned}
$$

where the wet $($ SPI $>1)$ and dry $($ SPI $<-1)$ exceedances relative to PRISM are combined for each model. The difference in CSI (WRF minus R2) provides a measure of added value of WRF. An increase in CSI is considered to add value by downscaling, as the simulated intensity of moderate to extreme wet and dry periods is improved.

The CSI for moderate to extreme events in WRF for the four accumulation periods is shown in Figure 5(a). The CSI averages around $50 \%$ for all accumulation periods. The highest CSI values (exceeding the $50 \%$ average) occur for the Northwest and West regions. The lowest CSI percentages are east of the Rockies, especially the southern and central US (lower than the 50\% average). The regional CSI values (Figure 5), along with the SPI correlations (Figure 4), indicate that WRF simulates the intensity of moderate to extreme wet events better for the western portions of the CONUS. As in WRF, the CSI is also larger over the western portions of the CONUS in R2 (Figure 5(b)) demonstrating the controlling 


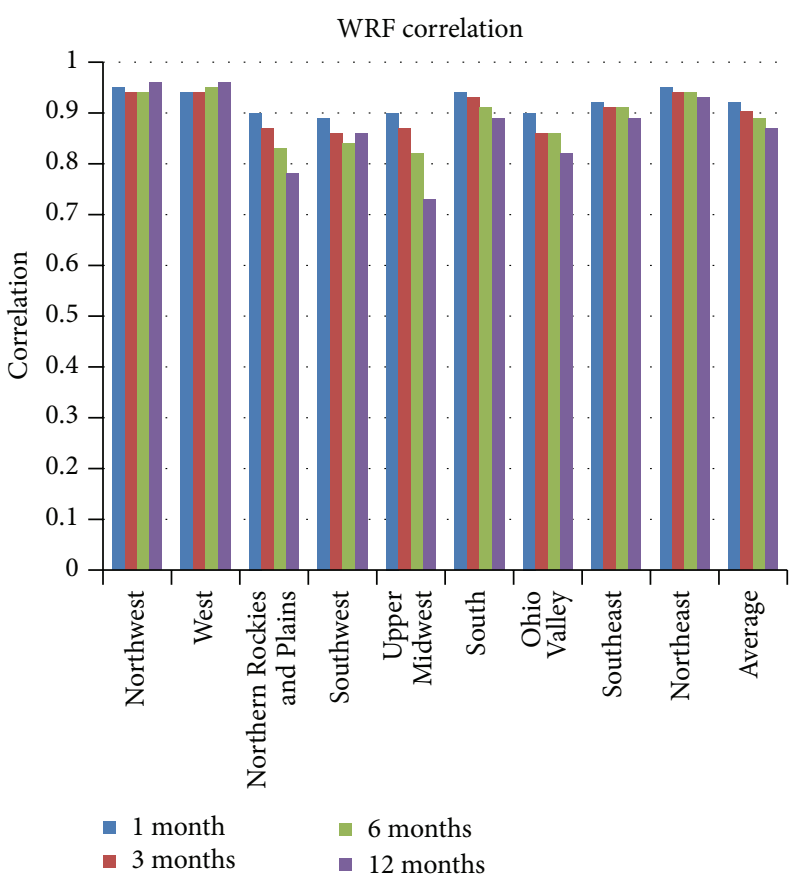

(a)

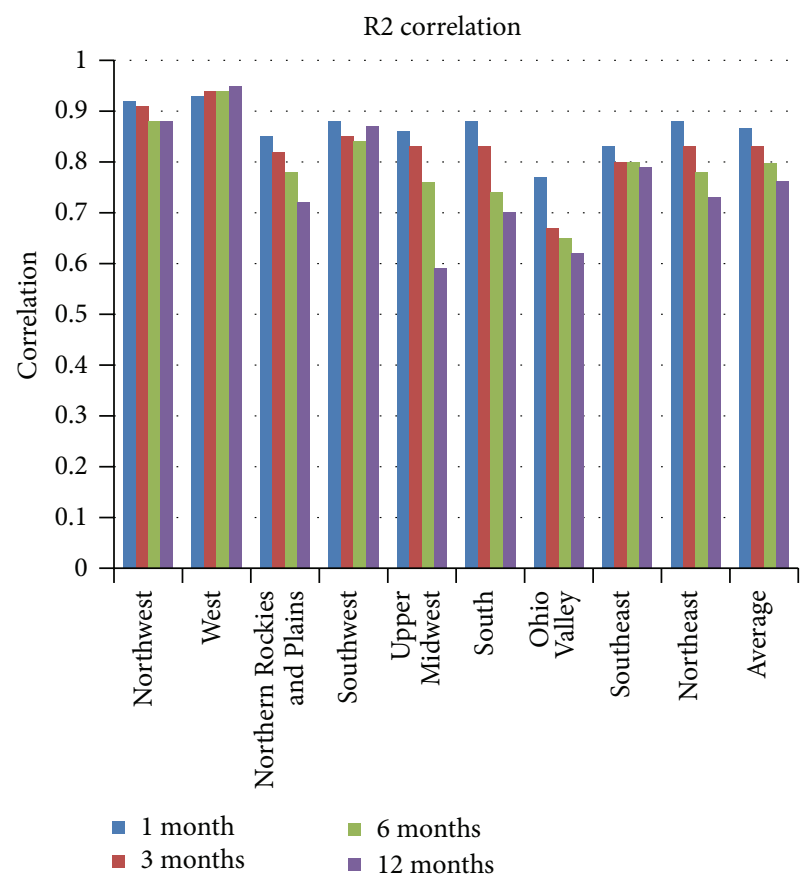

(b)

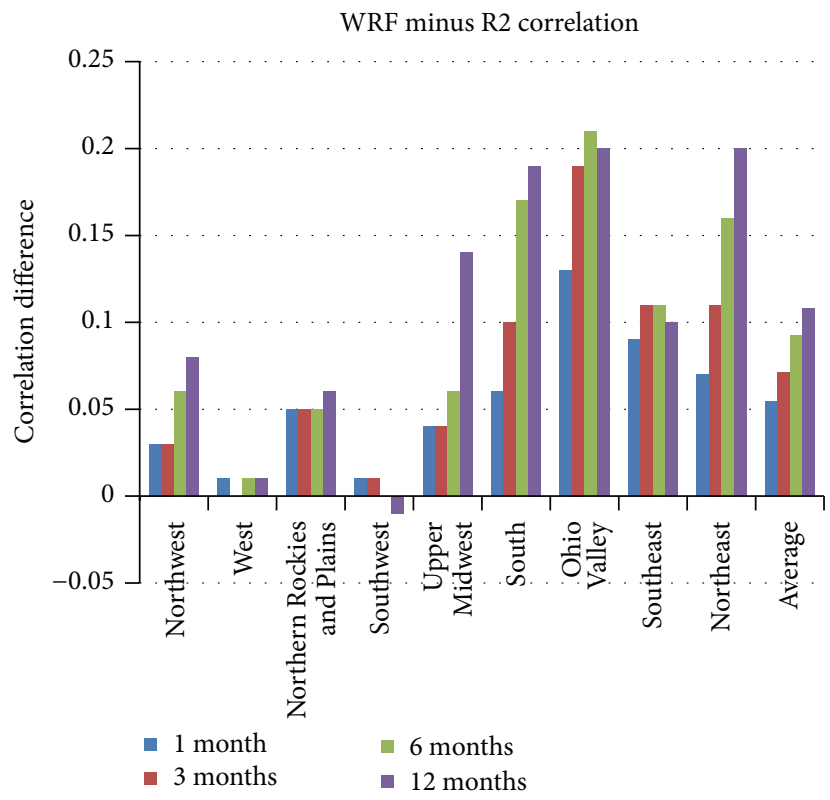

(c)

FIGURE 4: SPI correlation coefficient between (a) WRF and PRISM and (b) R2 and PRISM for 1-, 3-, 6-, and 12-month accumulation periods averaged over each NCDC climate region. (c) Difference between WRF and R2 correlation coefficient (WRF minus R2) for the same periods and regions as in (a) and (b).

influence of the large-scale atmospheric forcing for SPI values.

Figure 5(c) compares the CSIs for moderate to extreme exceedances from WRF and R2. In general, the CSI is larger in WRF for the majority of the CONUS, which demonstrates there is added value by dynamical downscaling. Across the regions and accumulation periods, there are several instances of the CSI for wet and dry events increasing with
WRF by more than $15 \%$ compared to R2. In particular, the Northeast region has the largest overall improvement in CSI by downscaling, especially for longer accumulation periods. On average, across the CONUS, WRF provides more value for longer accumulation periods, though overall CSI improves by $5-10 \%$ for each accumulation period. While projections of moderate to extreme dry and wet periods are improved by downscaling, added value for these events is spatially 


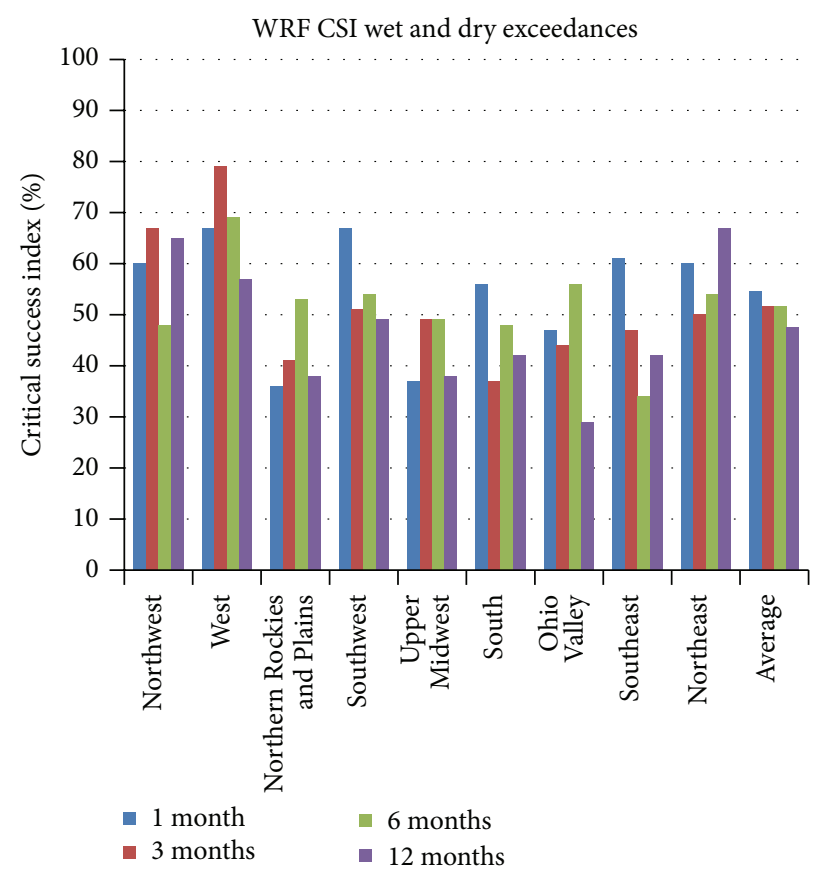

(a)

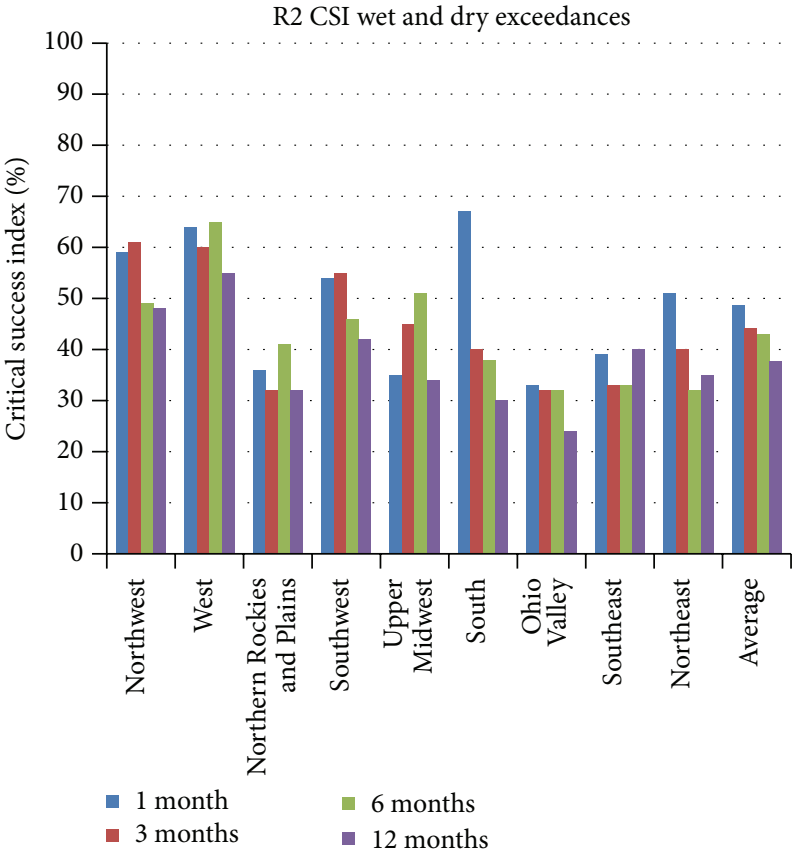

(b)

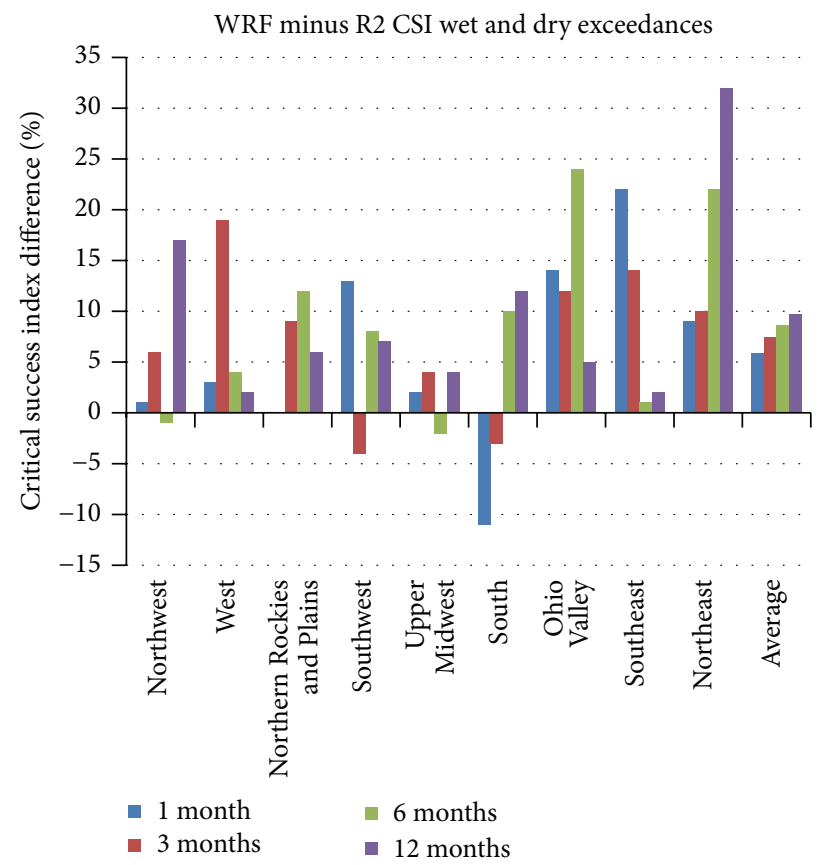

(c)

FIGURE 5: CSI for $\mid$ SPI $>1$ between (a) WRF and PRISM and (b) R2 and PRISM for 1-, 3-, 6-, and 12-month accumulation periods averaged over each NCDC climate region. (c) Difference between WRF and R2 CSI (WRF minus R2) for the same periods and regions as in (a) and (b).

inconsistent which indicates the complexity of assessing added value using a RCM for moderate to extreme dry or wet periods. For instance, the added value in the Northeast from downscaling may result from improvements in simulating the mesoscale circulation and precipitation when using a RCM, such as latent heating in midlatitude cyclones [11]. By contrast, smaller improvements over the western U.S. suggest that the large-scale atmospheric circulation in R2 (which was retained in WRF through the lateral boundaries and by nudging) sufficiently resolves droughts and floods in those regions.

\section{SPI Event Analysis}

Examining the SPI during significant meteorological events can provide further insight into added value by downscaling 


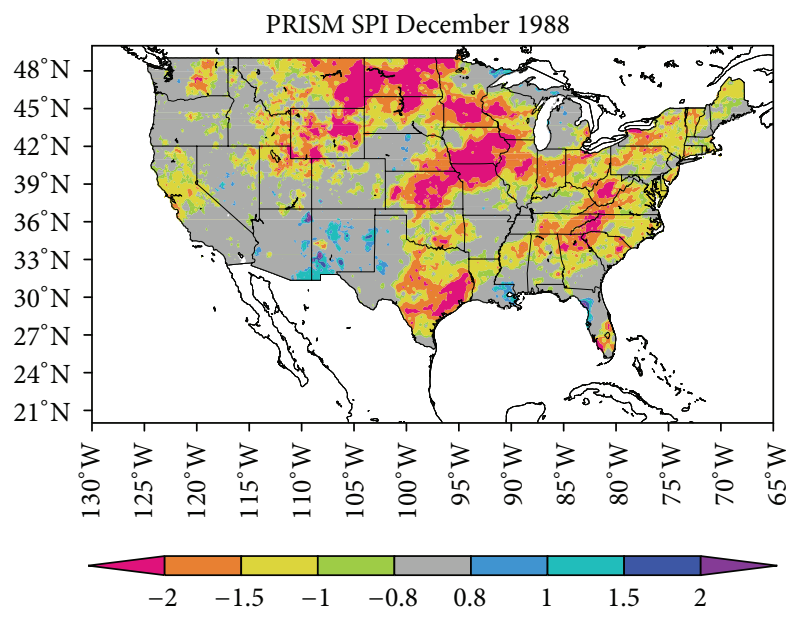

(a)

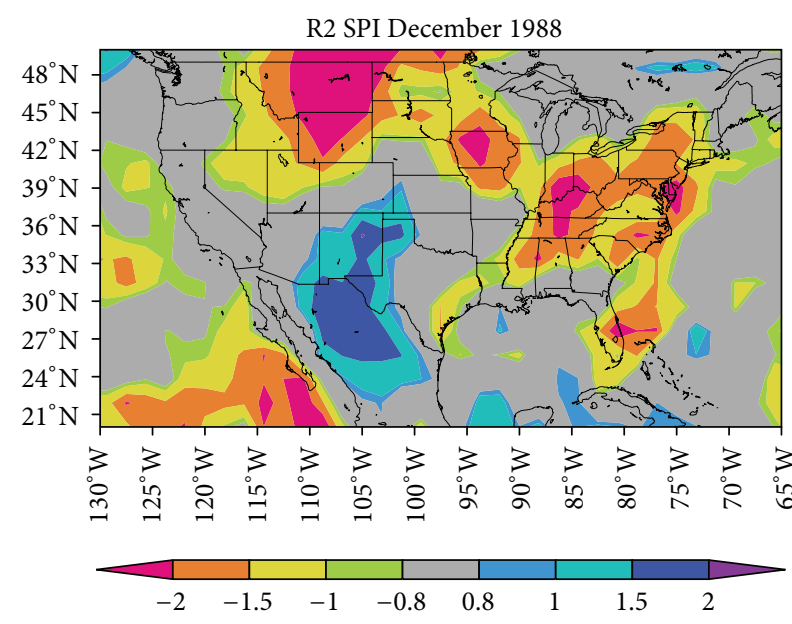

(b)

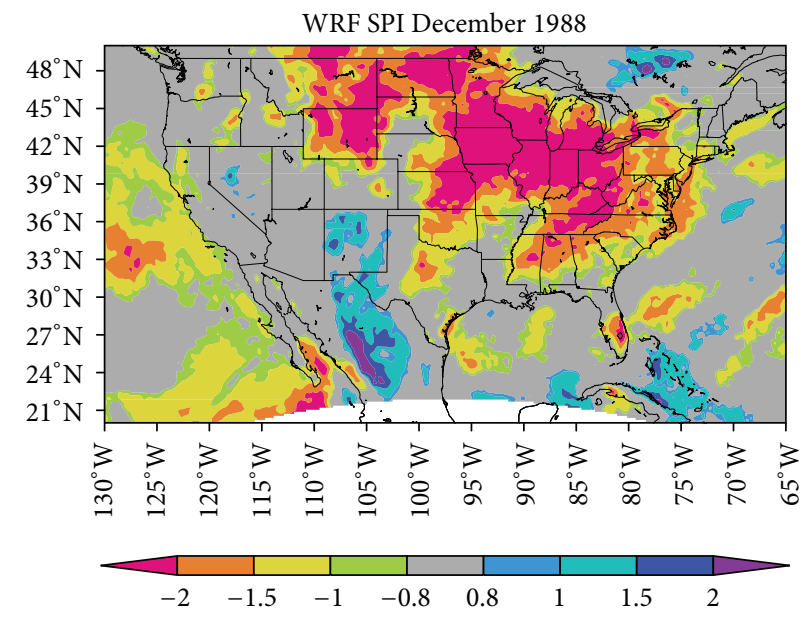

(c)

FIGURE 6: 12-month SPI ending in December 1988 calculated from (a) PRISM, (b) R2, and (c) WRF.

with a RCM [9]. Using the North American drought of 1988, we investigate the effects of downscaling on a widespread drought caused by shifts in large-scale atmospheric circulation that are resolved by the driving data. Our second type of event analysis focuses on three tropical cyclones that ended regional drought conditions during the 1990 and 1999 Atlantic hurricane seasons. Tropical cyclones are known to have "drought busting" capabilities such that as many as $41 \%$ of all droughts in the Southeastern U.S. are ended by them [33]. The storms examined here highlight very different "drought busting" events: Tropical Storm Marco in 1990, and Hurricanes Dennis and Floyd in 1999.

5.1. North American Drought of 1988. The 1988 drought is the costliest U.S. drought during the historical period of this study with estimated $\$ 39$ billion in damage to agriculture and related industries [34]. That drought occurred during a strong La Niña event, which displaced North American storm tracks farther north into Canada [35]. The intensity and magnitude of the North American drought of 1988 can be discerned from the SPI based on PRISM for the 12-month period ending in December 1988 (Figure 6(a)). Much of the Northern Plains and Rockies, Midwest, and parts of the Gulf and Atlantic Coasts were experiencing severe to extreme levels of drought. Conversely, some parts of the southwestern U.S. were abnormally wet, with SPI values between +1 and +2 from the PRISM data.

As expected, R2 broadly captures the large-scale spatial patterns of the drought and the abnormally wet area in the southwestern U.S. (Figure 6(b)). However, the SPI values are locally improved relative to observations by downscaling with WRF (Figure 6(c)), particularly within the complex terrain of the Cascade and Appalachian Mountains (Figure 6(a)). Within the Cascade Mountain range, R2 underestimates the observed moderate drought conditions in Washington and Oregon and overestimates the drought conditions in Idaho. WRF better represents the location of the moderate drought conditions at local scales within many western states including Oregon, Washington, Idaho, and Nevada. In the Appalachian Mountains, moderate to extreme drought was observed from western North Carolina and eastern Tennessee northeastward to West Virginia. R2 underestimates 
the severity of the drought for these locations, while WRF improves representation of the intensity and placement of the drought. Some of the largest differences occur in Kansas and Oklahoma, an area with fairly uniform terrain and extensive agriculture and ranching. The horizontal resolution of R2 cannot resolve the gradient between wetter conditions in the Southwest and drought in the Great Plains. WRF captures the intensity and location of the drought within Kansas and Oklahoma while also improving the placement and magnitude of the wetter conditions in the Southwest. The SPI computed from WRF also has some shortcomings: notably, the overpredicted intensity of the drought in the Upper Midwest and Ohio Valley and the miss of the drought along the Texas coast. Overall, this example illustrates that downscaling can add value at local scales when using SPI to characterize the spatial extent of droughts.

5.2. 1990 Tropical Storm Marco. Tropical Storm Marco dumped locally heavy amounts of rainfall between October 10 and October 13, 1990, across parts of the Southeast U.S., exceeding 10 inches in many locations throughout Georgia, South Carolina, and North Carolina [33, 36]. The heavy rainfall and associated flooding caused $\$ 57$ million in damage and was responsible for 7 deaths [37]. Tropical Storm Marco was noteworthy because of its role in the formation and evolution of two mesoscale features (cold-air damming and coastal frontogenesis) over Georgia and the Carolinas that enhanced the local precipitation over these areas on October 10 and October 11. These mesoscale features formed while Tropical Storm Marco was centered over southern and central Florida more than $400 \mathrm{~km}$ away [33, 36]. Prior to Tropical Storm Marco, Southeastern Atlantic states were experiencing drought conditions [33]. Below we compare the SPI values before and after Tropical Storm Marco to evaluate the added value of WRF for a "drought busting" tropical cyclone that induces mesoscale features important for rainfall totals.

Figure 7(a) illustrates the observed drought using the 6month SPI calculated from PRISM prior to the landfall of Tropical Storm Marco in October 1990. The SPI values are less than -2 (extreme drought) in many locations throughout the Southeast. Figures 7(b) and 7(c) show the 6-month SPI values from R2 and WRF for the same period. The drought using $\mathrm{R} 2$ is farther west and misses the drought that extends from Georgia into South and North Carolina. In comparison, WRF is able to capture drier conditions over Georgia extending into South Carolina, but the magnitude of the drought is less intense than observed. Note that the most intense drought in WRF, with SPI values less than -2 , follows the general pattern reflected in $\mathrm{R} 2$ with the driest conditions farther west into Louisiana and Mississippi.

After Tropical Storm Marco made landfall, the extreme drought in southern Georgia was alleviated (compare Figures $7(\mathrm{a})$ and $8(\mathrm{a})$ ). Additionally, there is a reversal in the SPI towards wetter than average conditions in central and western portions of North and South Carolina. Although WRF underestimated the intensity of the drought, especially for Southeastern Georgia (compare Figures 7(a) and 7(c)), it captures the relative shift towards neutral conditions. However, the reversal in the SPI values in WRF and R2 is similar for the Southeastern Atlantic states and neither has a strong reversal in the SPI values as observed. Comparing the SPIs from R2 and WRF indicates that WRF provides relatively small value in this case despite Tropical Storm Marco's role in the formation of mesoscale features that led to copious amounts of rainfall.

5.3. 1999 Hurricanes Dennis and Floyd. The 1999 Atlantic hurricane season included Hurricane Floyd, which generated the costliest flooding event in North Carolina history with an estimated total cost exceeding \$9 billion [34]. The back-toback combination of Hurricanes Dennis and Floyd in AugustSeptember 1999 altered the regional and local drought signals in parts of the eastern seaboard of the U.S. as the region transitioned out of a period of prolonged drought. In particular, the tracks of Dennis and Floyd crossed eastern North Carolina less than two weeks apart, resulting in historic flooding of the Tar River and inundation of the town of Princeville [38]. The localized heavy rainfall, especially over eastern North Carolina, provides another ideal event to investigate the added value of increasing the horizontal resolution for simulating "drought busting" tropical cyclones.

Prior to Hurricanes Dennis and Floyd in 1999, much of the Mid-Atlantic and Northeast was experiencing a longterm moderate to extreme drought, as evident in the 12month SPI calculated from PRISM and ending in July 1999 (Figure 9(a)), particularly seen from North Carolina into the Mid-Atlantic states with SPI values less than -1 . The passages of Hurricanes Dennis and Floyd in late August and early September, 1999, respectively, brought relief to drought-stricken areas along the Atlantic coast. Those storms shifted the moderate-extreme drought in July 1999 to nearly neutral conditions for most locations east of the Appalachian Mountains after the storms, as seen by comparing the 12month SPI ending in July 1999 (Figure 9(a)) to that ending in September 1999 (Figure 10(a)). Eastern North Carolina and Southeastern Virginia experienced historic flooding during this time, and the precipitation received from these storms over this short period completely reversed the 12-month SPI to abnormally wet conditions, as reflected in the local SPI values above +2 in some areas (Figure 10(a)). Portions of the Ohio Valley states, which did not receive precipitation from those storms (not shown), remained in extreme drought.

WRF provides a better estimate of the drought for the 12month SPI ending in July 1999 than R2 prior to Hurricanes Dennis and Floyd, especially for the Northeastern states (see Figures 9(b) and 9(c)). For instance, WRF correctly identified the drought extending into Northern New York, Vermont, and New Hampshire, but it was absent in R2. Figure 9 clearly shows that the coarser horizontal resolution in R2 limits the ability to capture transition regions of wet and dry conditions, as in Northern New York. Figure 10 shows that, after the passages of Hurricanes Dennis and Floyd, both R2 and WRF captured the relief of the long-term drought conditions for locations east of the Appalachian Mountains, especially notable in North Carolina and Virginia. WRF improves the spatial gradient of the SPI values relative to R2, 


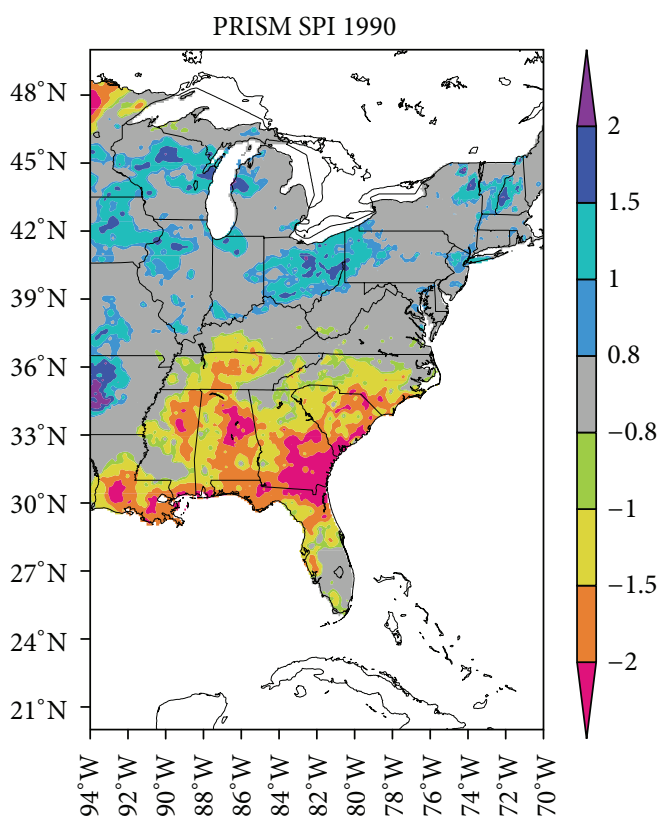

(a)

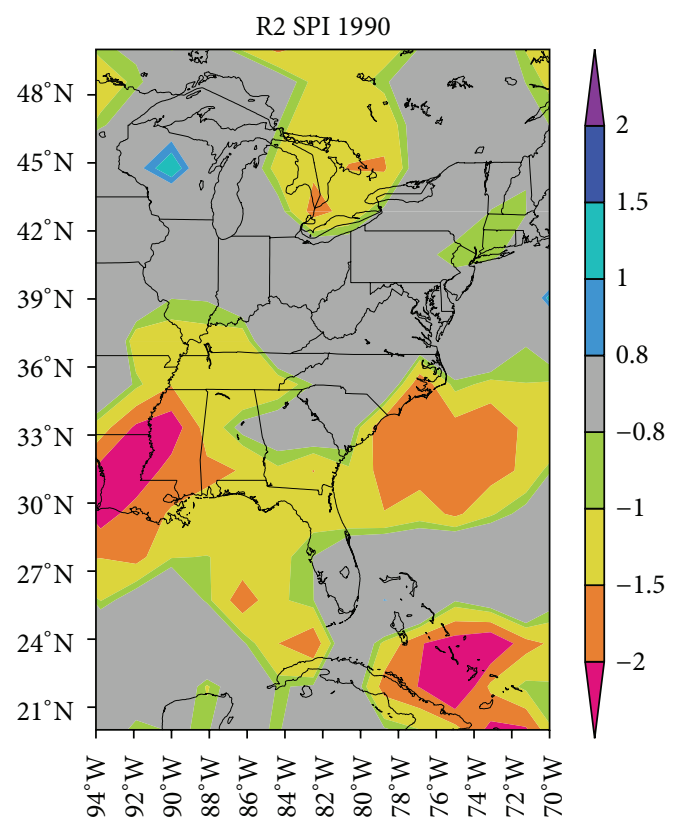

(b)

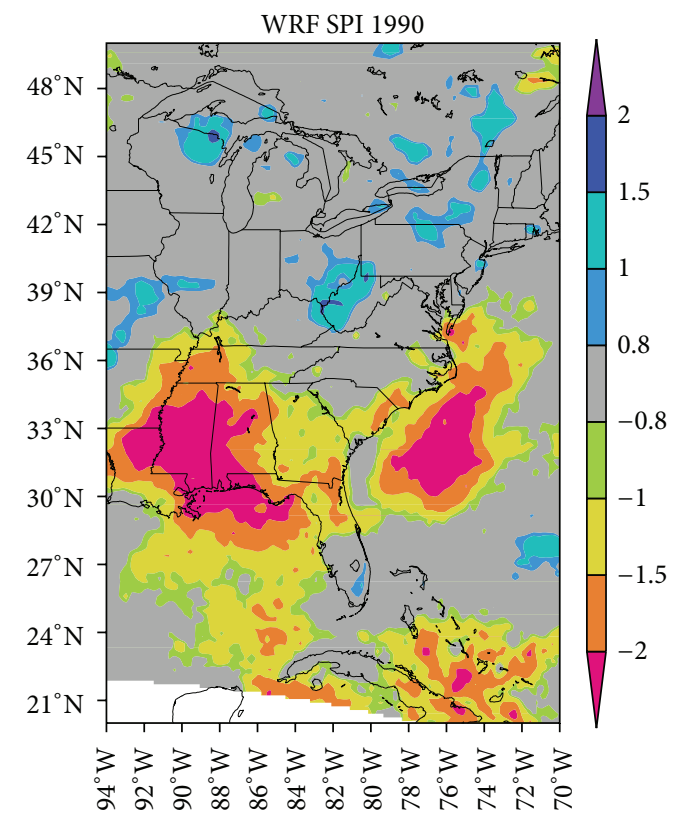

(c)

FIGURE 7: 6-month SPI for the period ending in September 1990 calculated from (a) PRISM, (b) R2, and (c) WRF.

but the magnitude of the SPI changes in WRF is smaller than observed, particularly in eastern North Carolina.

\section{Discussion and Conclusions}

WRF's performance was compared against that of the largescale input data (R2) to gauge the added value of using downscaling to predict drought over a historical period by using the SPI as the drought metric. The $36-\mathrm{km}$ horizontal grid spacing used here in WRF is similar to many large-scale coordinated experiments, and these results may provide insight into the value of calculating SPI for these experiments. SPI can be calculated for different accumulation periods to project the impact of precipitation totals on agriculture and water resources. In this study, the quantitative evaluation compares R2 and WRF to PRISM observations and includes the correlation and the CSI for moderate to extreme wet and dry events. Additionally, this study uses an event analysis to assess the added value of computing the SPI from dynamically downscaled fields. 


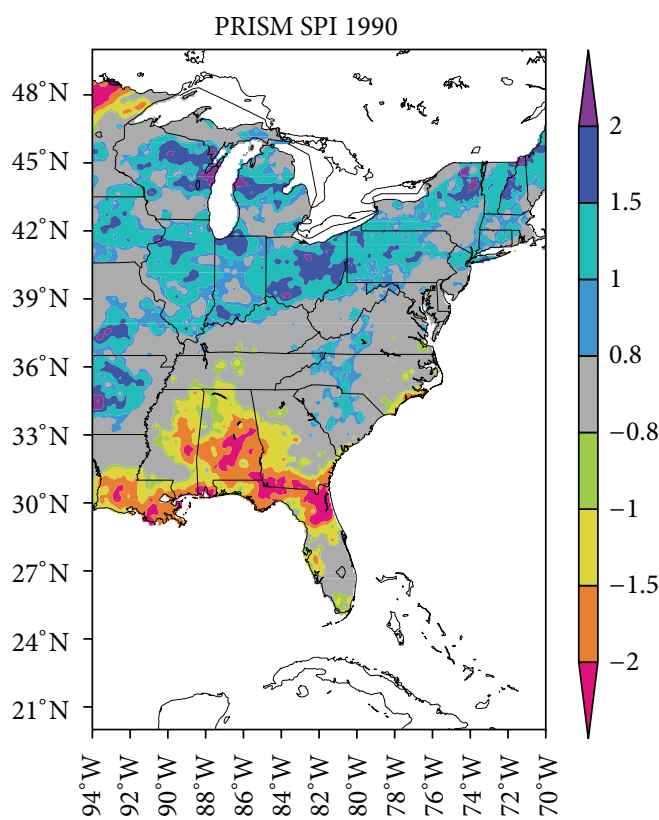

(a)

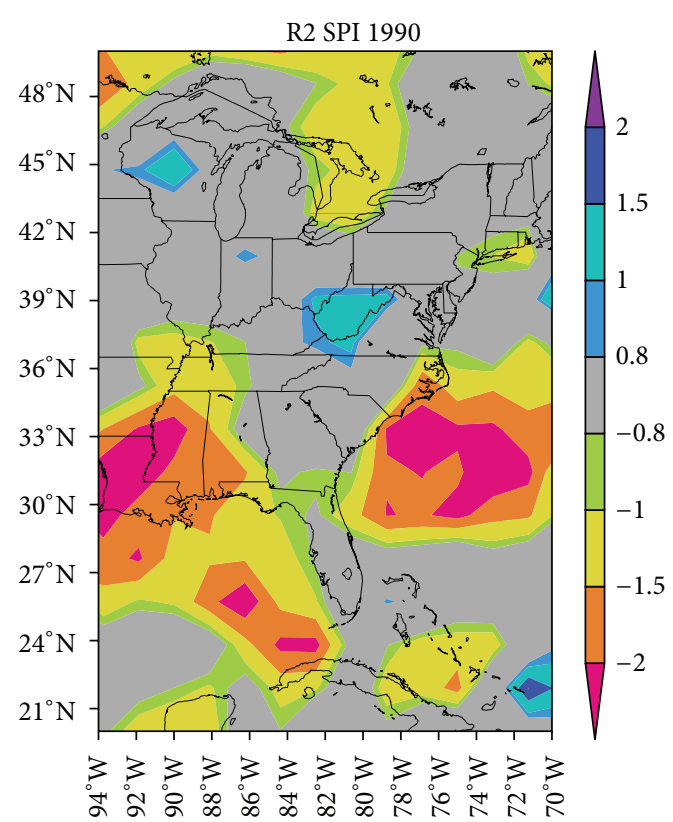

(b)

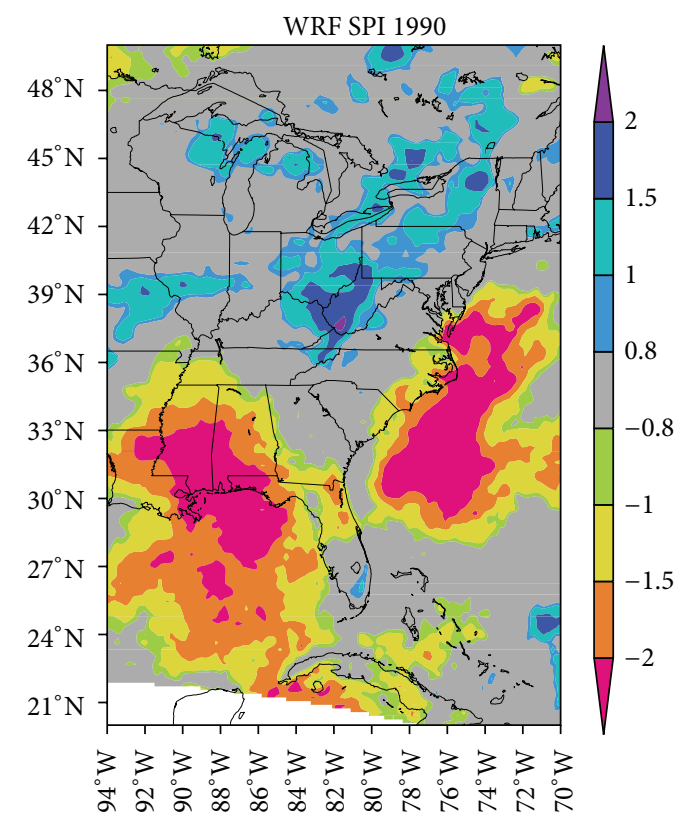

(c)

Figure 8: As in Figure 7, but for the period ending in October 1990.

The SPI correlation with observations decreases for longer accumulation periods in both R2 and WRF and demonstrates the influence of the large-scale atmospheric forcing on the SPI values. In general, SPI values in WRF follow R2 as expected, but WRF also provides added value at the NCDC regional scales. The largest added value occurs for longer accumulation periods. The implication of this result is that water resource applications (e.g., water storage within reservoirs) may benefit more when using dynamically downscaled precipitation. The regional scale statistics, including the CSI calculation for moderate to extreme dry and wet events, also reveal that WRF adds value for extreme/wet dry events and in areas without complex terrain. The results indicate that downscaling is particularly beneficial to categorize the intensity of moderate to extreme wet and dry periods, especially within NCDC regions east of the Rockies.

Because averaging SPI values over large regions can sometimes mask the local variations within a NCDC climate region, particularly when a region includes areas with SPI values of the opposite sign, we examined SPI 


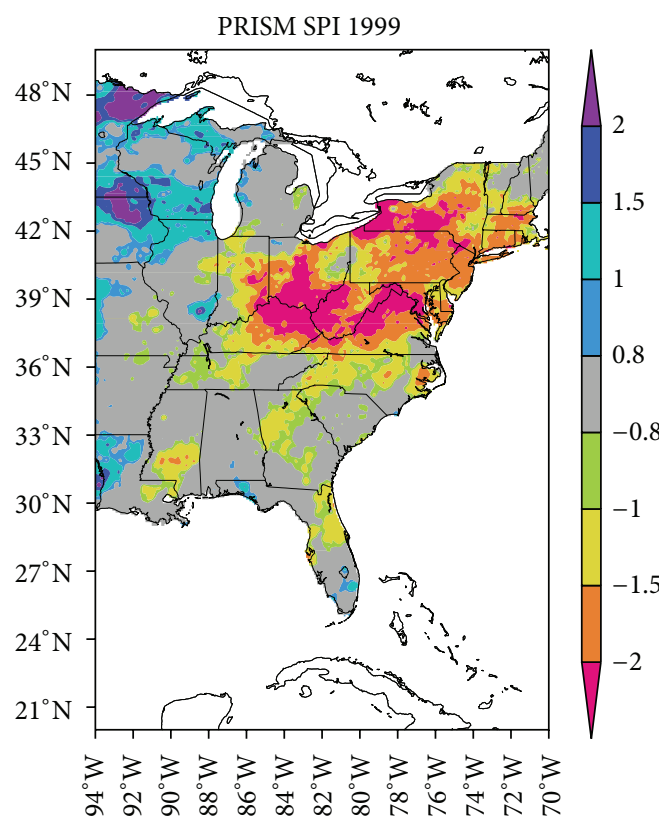

(a)

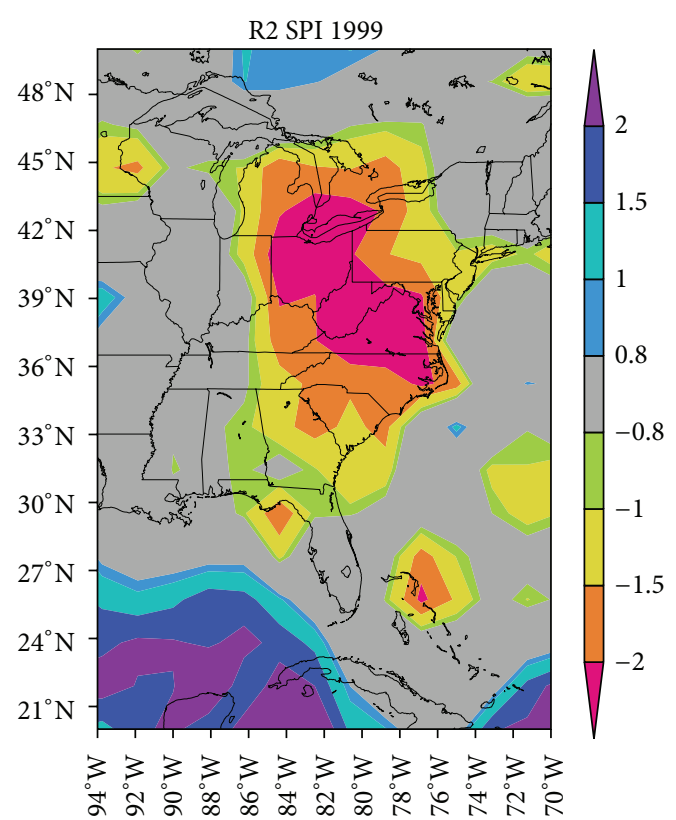

(b)

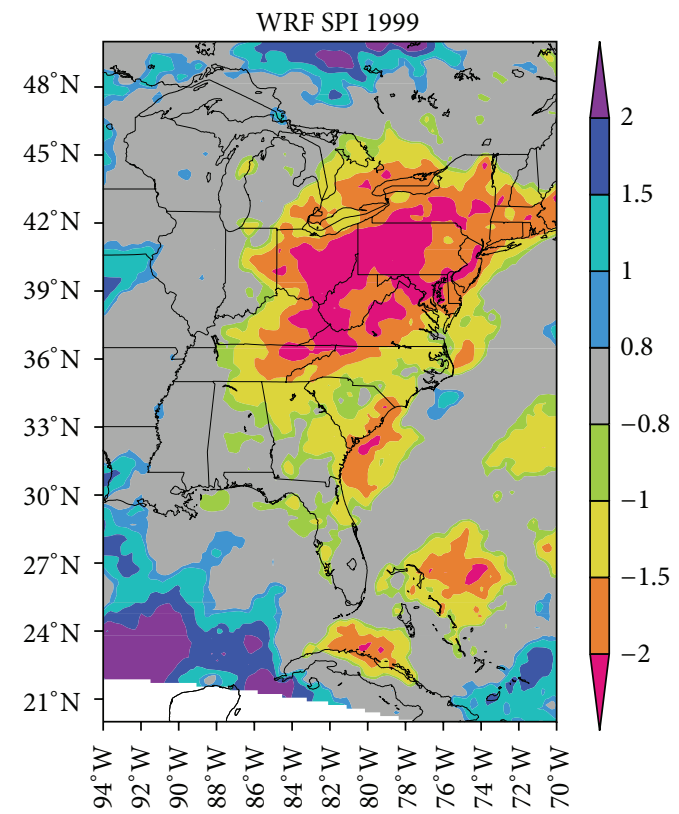

(c)

FIGURE 9: 12-month SPI for the period ending in July 1999 calculated from (a) PRISM, (b) R2, and (c) WRF.

predictions spatially using events with important local effects. For the 1988 North American drought, WRF improved the drought placement and magnitude within the NCDC regions. Many times added value is associated with betterresolved terrain, land use, and land/water boundaries. The 1988 North American drought occurred in regions without complex terrain, such as the Great Plains. The Great Plains was a transition region in R2 between extremely dry and wet areas, and the coarse resolution of R2 failed to capture some areas of drought as large as the states of Kansas and Oklahoma. By contrast, WRF better simulates the location and intensity of the drought because it resolves the SPI gradient. The significance of this result is that large-scale droughts, despite being generally associated with large-scale atmospheric circulation shifts and resolvable by the driving data, are better resolved with dynamical downscaling in both regions with and without complex terrain.

We also examined the added value of using a RCM for "drought busting" tropical cyclones. Tropical Storm Marco (1990) and Hurricanes Dennis and Floyd (1999) reveal that the reversal of SPI values to wet or near normal conditions after a prolonged drought is typically underestimated and 


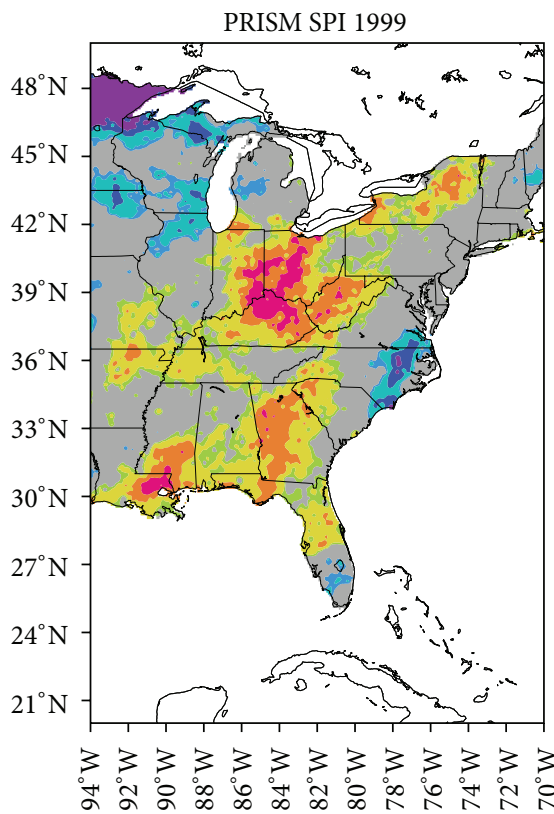

(a)
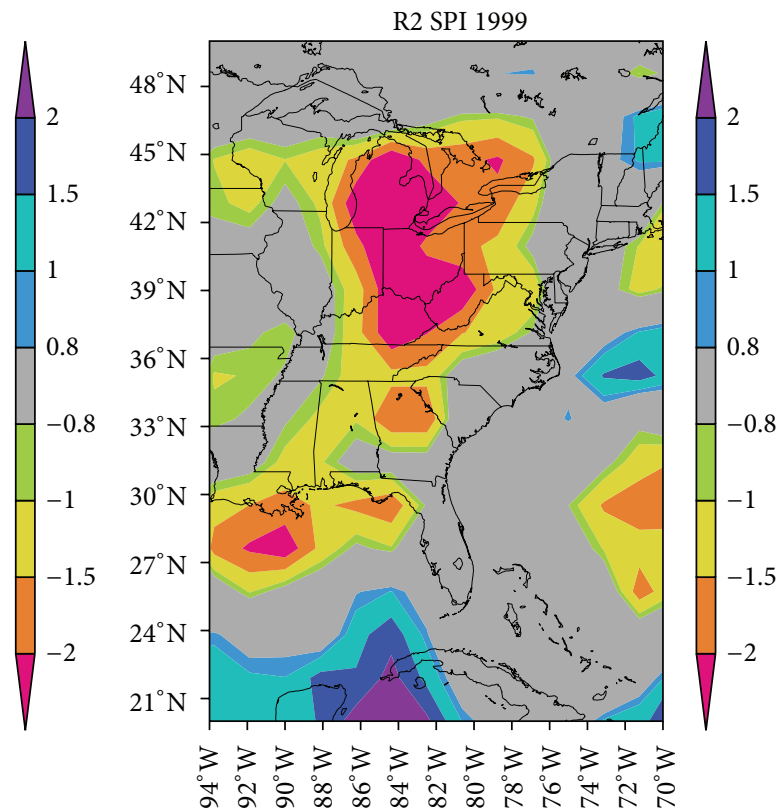

(b)

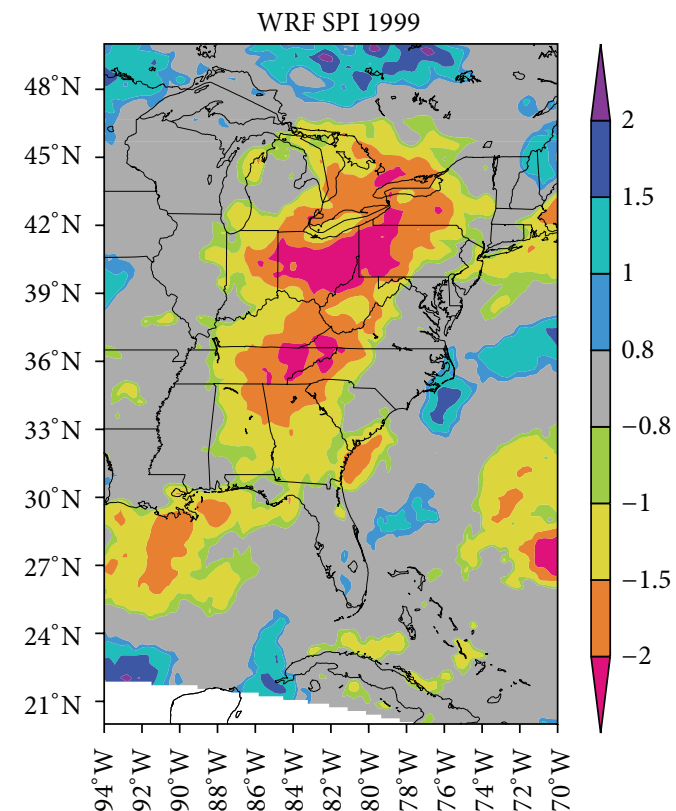

(c)

FIGURE 10: As in Figure 9, but for the period ending in September 1999.

thus the impact of tropical storms as "drought busters" is also underestimated by both R2 and WRF. This information may be important for RCM applications, such as those from largescale coordinated downscaling experiments. Tropical Storm Marco was a complex system that induced mesoscale features important for rainfall and ended the ongoing drought while Hurricanes Dennis and Floyd made a direct impact on the rainfall totals. The relative differences in the SPI values from Tropical Storm Marco and Hurricanes Dennis and Floyd illustrate that added value can be storm dependent. For Hurricanes Dennis and Floyd, the added value of using downscaled fields to compute SPI values was easily identified as the transition regions between wet and dry locations were improved in WRF relative to R2. For Tropical Storm Marco, SPI values were similar between R2 and WRF and may be an artifact of $36-\mathrm{km}$ resolution when considering simulating tropical storm induced cold-air damming and coastal frontogenesis. Overall, many coordinated RCM efforts use a comparable horizontal resolution to that used here, and our results illustrate that there is added value in using a RCM for drought assessments that may also be applicable to those groups. 


\section{Conflict of Interests}

The authors declare that there is no conflict of interests regarding the publication of this paper.

\section{Acknowledgments}

The PRISM precipitation analyses are courtesy of the PRISM Climate Group at Oregon State University and were obtained from http://www.prism.oregonstate.edu/. The authors thank Lara Reynolds (CSC) for assistance in developing the simulations that were used in this analysis. Valuable discussions with Ryan Boyles (State Climatologist of North Carolina) contributed to the formulation of this research concept. The authors thank Brian Eder (U.S. EPA) and the anonymous reviewer for their technical reviews of this paper. The U.S. Environmental Protection Agency through its Office of Research and Development funded and managed the research described here. It has been subjected to the Agency's administrative review and approved for publication.

\section{References}

[1] J. Keyantash and J. A. Dracup, "The quantification of drought: an evaluation of drought indices," Bulletin of the American Meteorological Society, vol. 83, no. 8, pp. 1167-1180, 2002.

[2] D. A. Wilhite, "Drought as a natural hazard: concepts and definitions," in Drought: A Global Assessment, vol. 1, pp. 1-18, Routledge, New York, NY, USA, 2000.

[3] A. Dai, "Increasing drought under global warming in observations and models," Nature Climate Change, vol. 3, no. 1, pp. 52$58,2013$.

[4] G. Nikulin, C. Jones, F. Giorgi et al., "Precipitation climatology in an ensemble of CORDEX-Africa regional climate simulations," Journal of Climate, vol. 25, no. 18, pp. 6057-6078, 2012.

[5] L. O. Mearns, W. Gutowski, R. Jones et al., "A regional climate change assessment program for North America," Eos, Transactions American Geophysical Union, vol. 90, no. 36, pp. 311-312, 2009.

[6] S. Blenkinsop and H. J. Fowler, "Changes in European drought characteristics projected by the PRUDENCE regional climate models," International Journal of Climatology, vol. 27, no. 12, pp. 1595-1610, 2007.

[7] P. Van Der Linden and J. F. B. Mitchell, Eds., ENSEMBLES: Climate Change and Its Impacts: Summary of Research and Results from the ENSEMBLES Project, Met Office Hadley Centre, Exeter, UK, 2009.

[8] X. Deng, C. Zhao, and H. Yan, "Systematic modeling of impacts of land use and land cover changes on regional climate: a review," Advances in Meteorology, vol. 2013, Article ID 317678, 11 pages, 2013.

[9] F. Feser, B. Rrockel, H. Storch, J. Winterfeldt, and M. Zahn, "Regional climate models add value to global model data a review and selected examples," Bulletin of the American Meteorological Society, vol. 92, no. 9, pp. 1181-1192, 2011.

[10] E. P. Salathé Jr., R. Steed, C. F. Mass, and P. H. Zahn, "A high-resolution climate model for the U.S. Pacific Northwest: mesoscale feedbacks and local responses to climate change," Journal of Climate, vol. 21, pp. 5708-5726, 2008.

[11] J. Willison, W. A. Robinson, and G. M. Lackmann, "The importance of resolving mesoscale latent heating in the North
Atlantic storm track," Journal of the Atmospheric Sciences, vol. 70, no. 7, pp. 2234-2250, 2013.

[12] T. C. Peterson, R. R. Heim Jr., R. Hirsch et al., "Monitoring and understanding changes in heat waves, cold waves, floods, and droughts in the United States: state of knowledge," Bulletin of the American Meteorological Society, vol. 94, no. 6, pp. 821-834, 2013.

[13] S. Schubert, D. Gutzler, H. Wang et al., "A U.S. Clivar project to assess and compare the responses of global climate models to drought-related SST forcing patterns: overview and results," Journal of Climate, vol. 22, no. 19, pp. 5251-5272, 2009.

[14] E. R. Cook, R. Seager, M. A. Cane, and D. W. Stahle, "North American drought: reconstructions, causes, and consequences," Earth-Science Reviews, vol. 81, no. 1-2, pp. 93-134, 2007.

[15] Y. Y. Hu, L. J. Tao, and J. P. Liu, "Poleward expansion of the hadley circulation in CMIP5 simulations," Advances in Atmospheric Sciences, vol. 30, no. 3, pp. 790-795, 2013.

[16] L. Li, W. Li, and Y. Deng, "Summer rainfall variability over the southeastern United States and its intensification in the 21st century as assessed by CMIP5 models," Journal of Geophysical Research: Atmospheres, vol. 118, no. 2, pp. 340-354, 2013.

[17] X. H. Meng, J. P. Evans, and M. F. Mccabe, "The impact of observed vegetation changes on land-atmosphere feedbacks during drought," Journal of Hydrometeorology, vol. 15, no. 2, pp. 759-776, 2014.

[18] C. F. Maule, P. Thejll, J. H. Christensen, S. H. Svendsen, and J. Hannaford, "Improved confidence in regional climate model simulations of precipitation evaluated using drought statistics from the ENSEMBLES models," Climate Dynamics, vol. 40, no. 1-2, pp. 155-173, 2013.

[19] S. Russo, A. Dosio, A. Sterl, P. Barbosa, and J. Vogt, "Projection of occurrence of extreme dry-wet years and seasons in Europe with stationary and nonstationary Standardized Precipitation Indices," Journal of Geophysical Research: Atmospheres, vol. 118, no. 14, pp. 7628-7639, 2013.

[20] W. C. Skamarock and J. B. Klemp, "A time-split nonhydrostatic atmospheric model for weather research and forecasting applications," Journal of Computational Physics, vol. 227, no. 7, pp. 3465-3485, 2008.

[21] M. Kanamitsu, W. Ebisuzaki, J. Woollen et al., "NCEP-DOE AMIP-II reanalysis (R-2)," Bulletin of the American Meteorological Society, vol. 83, no. 11, pp. 1631-1643, 2002.

[22] T. L. Otte, C. G. Nolte, M. J. Otte, and J. H. Bowden, "Does nudging squelch the extremes in regional climate modeling?" Journal of Climate, vol. 25, no. 20, pp. 7046-7066, 2012.

[23] J. S. Kain and J. Kain, "The Kain-fritsch convective parameterization: an update," Journal of Applied Meteorology, vol. 43, no. 1, pp. 170-181, 2004.

[24] J. H. Bowden, C. G. Nolte, and T. L. Otte, "Simulating the impact of the large-scale circulation on the 2-m temperature and precipitation climatology," Climate Dynamics, vol. 40, no. 7-8, pp. 1903-1920, 2013.

[25] J. H. Bowden, T. L. Otte, C. G. Nolte, and M. J. Otte, "Examining interior grid nudging techniques using two-way nesting in the WRF model for regional climate modeling," Journal of Climate, vol. 25, no. 8, pp. 2805-2823, 2012.

[26] T. B. McKee, N. J. Doesken, and J. Kleist, "The relationship of drought frequency and duration to time scales," in Proceedings of the 8th Conference on Applied Climatology, pp. 179-184, American Meteorological Society, Anaheim, Calif, USA, 1993. 
[27] M. J. Hayes, M. D. Svoboda, D. A. Wilhite, and O. V. Vanyarkho, "Monitoring the 1996 drought using the standardized precipitation index," Bulletin of the American Meteorological Society, vol. 80, no. 3, pp. 429-438, 1999.

[28] D. C. Edwards and T. B. McKee, "Characteristics of 20th century drought in the United States at multiple time scales," Climatology Report 97-2, Department of Atmospheric Science, Colorado State University, Fort Collins, Colo, USA, 1997.

[29] C. Daly, R. P. Neilson, and D. L. Phillips, "A statisticaltopographic model for mapping climatological precipitation over mountainous terrain," Journal of Applied Meteorology, vol. 33, no. 2, pp. 140-158, 1994.

[30] M. Svoboda, M. Hayes, and D. Wood, "Standardized precipitation index user guide," WMO 1090, World Meteorological Organization, Geneva, Switzerland, 2012.

[31] H. Wu, M. J. Hayes, D. A. Wilhite, and M. D. Svoboda, "The effect of the length of record on the standardized precipitation index calculation," International Journal of Climatology, vol. 25, no. 4, pp. 505-520, 2005.

[32] D. Kang, B. K. Eder, A. F. Stein, G. A. Grell, S. E. Peckham, and J. McHenry, "The new England air quality forecasting pilot program: development of an evaluation protocol and performance benchmark," Journal of the Air and Waste Management Association, vol. 55, no. 12, pp. 1782-1796, 2005.

[33] J. T. Maxwell, P. T. Soulé, J. T. Ortegren, and P. A. Knapp, "Drought-busting tropical cyclones in the Southeastern Atlantic United States: 1950-2008," Annals of the Association of American Geographers, vol. 102, no. 2, pp. 259-275, 2012.

[34] National Climatic Data Center (NCDC), Billion-Dollar U.S. Weather/Climate Disasters, National Climatic Data Center (NCDC), Asheville, NC, USA, 2013, http://www.ncdc.noaa .gov/billions/events.pdf.

[35] K. E. Trenberth and C. J. Guillemot, "Physical processes involved in the 1988 drought and 1993 floods in North America," Journal of Climate, vol. 9, no. 6, pp. 1288-1298, 1996.

[36] A. F. Srock and L. F. Bosart, "Heavy precipitation associated with Southern Appalachian cold-air damming and Carolina coastal frontogenesis in advance of weak landfalling Tropical Storm Marco (1990)," Monthly Weather Review, vol. 137, no. 8, pp. 2448-2470, 2009.

[37] M. Mayfield and M. B. Lawrence, "Atlantic hurricane season of 1990," Monthly Weather Review, vol. 119, no. 8, pp. 2014-2026, 1991.

[38] Upper Coastal Plain Council of Government, Town of Princeville, North Carolina: Hazard Mitigation Plan, 2004, http:// www.edgecombecountync.gov/client_resources/planning/princeville-mj-hm-plan.pdf. 

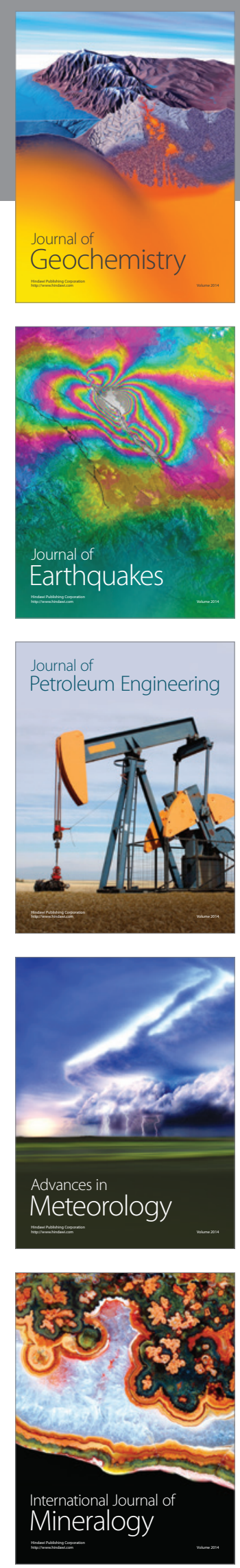
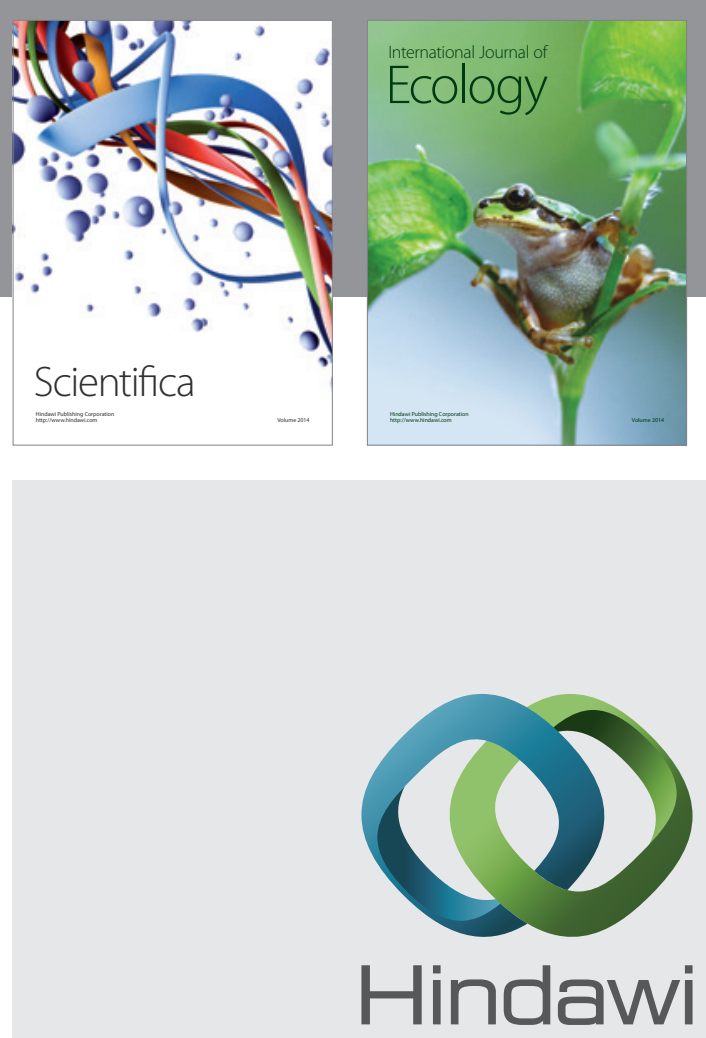

Submit your manuscripts at

http://www.hindawi.com
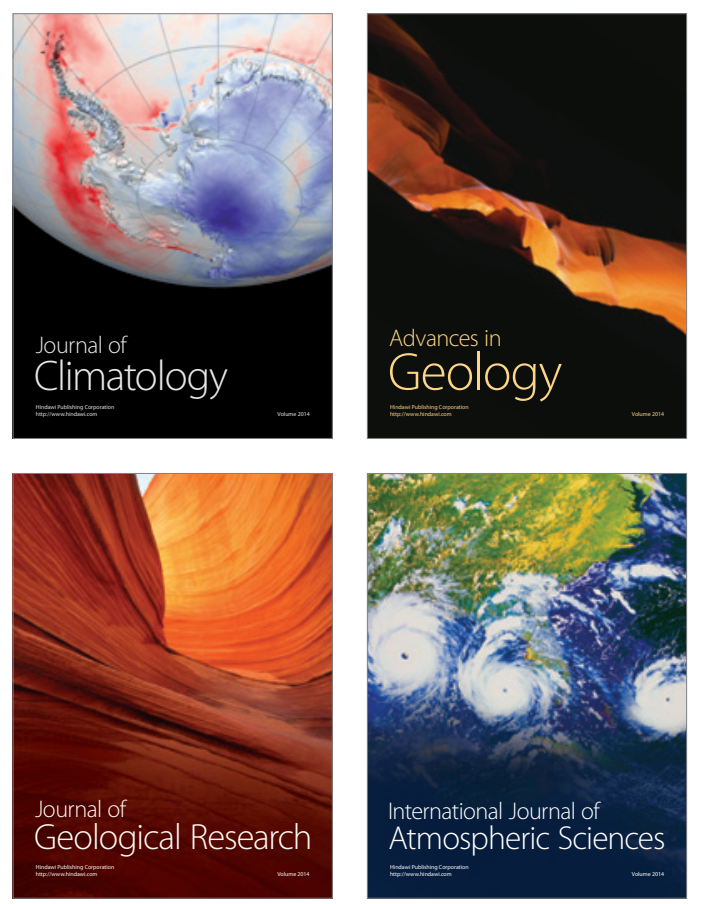

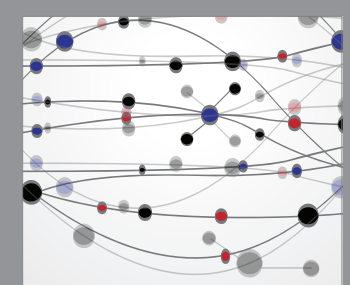

The Scientific

\section{World Journal}
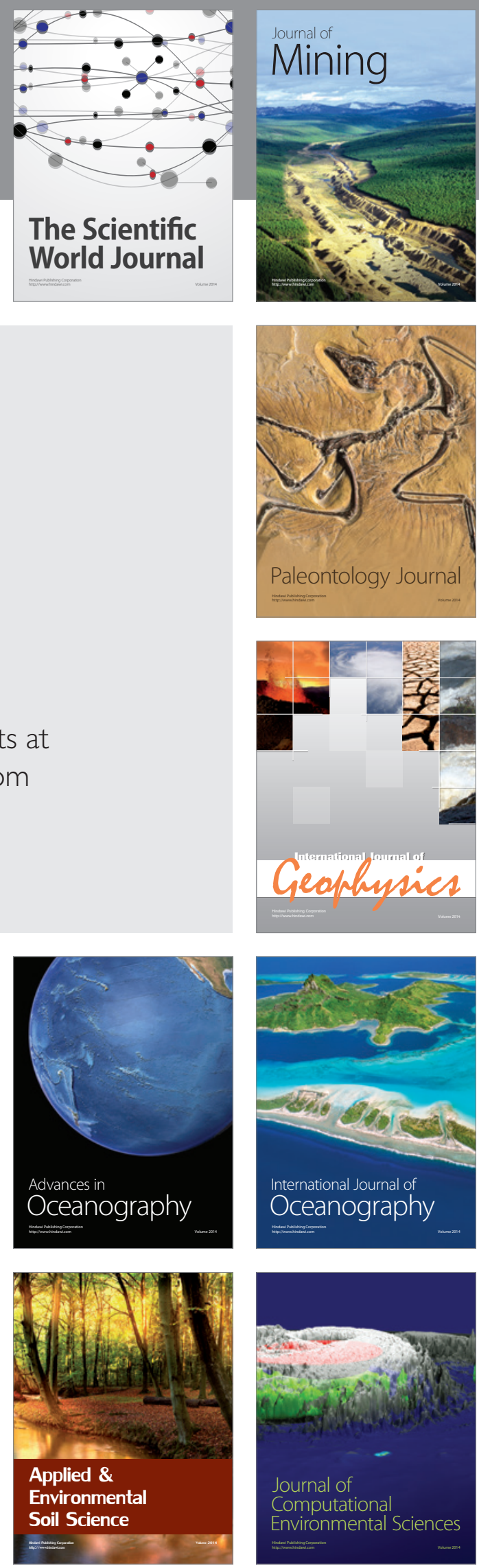